\title{
HANDOFF
}

\section{His Mother}

Ashish Verma, MD, MRCP

Maura J. Brennan, mD
Department of Medicine, Baystate Medical Center, Springfield, Massachussetts.

Supporting information is available online for this article and any future accepted manuscripts.

Disclosure: Nothing to report.
"Bertha Johnson is back with pneumonia again." The ED doctor on the telephone sounded both matter-of-fact and mildly bored when I answered her page about another admission to the hospitalist service. I hadn't met Mrs. Johnson previously, but came to know her and Douglas, her only son, well over the next few days.

The Johnsons were facing a difficult choice. Bertha was now bedbound and quadriplegic following a 40-year battle with multiple sclerosis and gradually mounting disability. She was cognitively intact and had a solid grasp of medical realities, but was hard of hearing and quite dysarthric. Forming even short phrases and sentences took great effort. However tenuous, this ability to speak allowed her to communicate with those she loved. She had been admitted thrice in the past year with aspiration pneumonia, as she was unable to clear her secretions reliably. Repeated bronchoscopies demonstrated an inability to protect her airway. Douglas, who was also her health care proxy, favored proceeding with the tracheostomy suggested by the pulmonary team. On a prior admission, he had been distressed when his mother refused this intervention. Now she was back with the identical problem and had been given the same recommendation by her doctors. It was particularly difficult for me to discuss these sensitive issues when I had not previously met either Bertha or her son. I spoke to her primary care physician over the phone and he agreed with the need for tracheostomy. The pulmonary team had been involved in discussions about tracheostomy in all of her hospital admissions, providing continuity of care in the process. Ultimately, it was my responsibility to help Bertha and Douglas come to a decision.

After multiple discussions between the Johnsons and me, a consensus emerged to proceed with the tracheostomy. We recognized that the procedure would increase her care needs and arranged for a stay in a skilled nursing facility to provide access to round-the-clock suctioning. The evening prior to the tracheostomy, the floor nurse and I reviewed the procedure to ensure that Bertha was fully prepared. What followed resulted in a drastic change of plan. Bertha emphasized that she did not want to lose her only means of communication, even if the surgery would prolong her life. She admitted that she reluctantly agreed to the procedure only to please her son and doctors, because they believed it to be in her best interest. Her fear of the prospect of death from drowning in her own secretions was much less than her fear of silence and isolation that would result from her loss of speech. I shared her misgivings with Douglas, and she admitted to him that she had only agreed to the procedure for his sake. We cancelled the surgery.

Douglas later revealed that he also had been ambivalent about the procedure for sometime, as it would necessitate a nursing home stay and the loss of the caretakers who had cared for his mother so wonderfully for many years. Bertha lived alone in her own home with the help of visiting nurses and patient care assistants Douglas paid for "out-of-pocket." Douglas lived and worked in a city over a hundred miles away, but managed to visit several times a month to facilitate his mother's care. He had supported the procedure only because the doctors had said it was the only way to avoid future pneumonias. The idea of a tracheostomy was definitively abandoned once and for all.

The Johnsons wanted Bertha to return to her home, but hospital case managers felt this would be an unsafe plan of care as she was alone for several hours a day. She was largely immobile and unable to escape if there were a fire or other emergency. Also, the caretakers were not trained to use the suction equipment, and the visiting nurses would only be available intermittently. The home care staff felt they could no longer meet her needs and declined to resume her care. Douglas became very frustrated by the delays and protracted negotiations, enough so that he threatened to sue the institution for "taking over my mother's life." The threat of litigation is usually a cry for help that reflects either miscommunication or the suffering of a conflicted family.

As their hospitalist, I hoped to advocate for both the patient and Douglas while coordinating the overall care plan. I had always received consistent responses from the Johnsons, but other staff members noted that Douglas had expressed shifting views on the best site of care for his mother. At Bertha's request, I convened a meeting with her, Douglas, the social worker, case manager, visiting and staff nurses, the palliative care nurse, and floor manager. Prior to this, I met with all involved health care providers to ensure we understood each other's abilities and limitations regarding Bertha's care. As I entered the room for the family meeting, I knew it was ultimately the patient's choice whether she wanted to return home or not-as long as she understood the risks involved.

During the meeting, all the team members explained the dilemmas they faced in planning for a safe disposition. Douglas's response illuminated his devotion and love for his 
ailing mother. He had known all along that it would be less expensive and burdensome for him for Bertha to be placed in a facility. However, he feared nursing home admission represented "giving up and failing to fulfill my duty to my mother." Tears ran down the face of this otherwise well composed, immaculately dressed, articulate man in his late forties. He had assumed the responsibility for his mother's care while still a child and had carried this self-imposed moral burden his entire life. This meeting was his first opportunity to voice explicitly to the medical team his immense love and concern for his dear mother.

I gently probed to clarify Bertha's values and goals. On a brief, prior nursing home stay, Bertha had found the experience to be "scary" and unfamiliar. However, as her functional abilities continued to decline, her feelings had changed. She now felt lonely and anxious at home when her caretakers were absent. She actually wanted to go to a nursing home, where there would always be company and support available! She had not told Douglas this because she knew he cared for her deeply and she "didn't want to hurt his feelings"; he seemed committed to caring for her the same way he had for so many years.

In short, Douglas knew it would be easier for him if his mother were in a nursing facility, but assumed she wanted to stay in her home. Oddly, Bertha was only remaining at home because she believed that was what her son wished. A few days later, Bertha was transferred to a nursing home near several relatives who would visit her regularly. Douglas was again selfless in not seeking to move her closer to him. He didn't want to uproot her more than was unavoidable.
Day-to-day practice reveals many examples of love and dedication, but I have never seen such blinding and unquestioning commitment as exemplified by this motherson duo. From them, I learned the importance of attentive and active listening. Our polite patients may only subtly hint at matters of the deepest import. If we cannot truly "hear" their unspoken emotions, we risk harming them and misinterpreting their words and actions. Some healthcare providers had seen Douglas as aggressive and demanding with his threat of a lawsuit, whereas Bertha had been described as "unrealistic" or "in denial." These views distorted a much more complex reality. Time and attention to careful communication between the healthcare providers, the patient, and her son bore fruit in this case. The "procedure" that was really needed was the family meeting and not the tracheostomy! An undesired and invasive procedure was avoided, goals of care were clarified, quality of life maximized, a safe discharge arranged, and a new mutual understanding achieved. I was humbled, and reminded of the importance of team-based care and the need to approach each patient and family member in a receptive, nonjudgmental, and open manner. Douglas and Bertha Johnson were linked with a profound and abiding bond that would only be severed at death.

\section{Address for correspondence and reprint requests:}

Ashish Verma, MD, 759 Chestnut Street, Springfield Massachusetts 01199; Telephone: 413-794-4320; Fax: 413-794-1767; E-mail: ashishvermamd@gmail.com; ashish.verma@bhs.org Received 3 May 2010; revision received 1 September 2010; accepted 7 September 2010. 